\title{
Tyrosine Phosphorylation Modulates the Vascular Responses of Mesenteric Arteries from Human Colorectal Tumors
}

\author{
Eduardo Ferrero, ${ }^{1}$ María Dolores Mauricio, ${ }^{2,3}$ Miriam Granado, ${ }^{4}$ \\ Oscar García-Villar, ${ }^{1}$ Martín Aldasoro, ${ }^{2,3}$ José María Vila, ${ }^{2,3}$ \\ Manuel Hidalgo, ${ }^{1}$ Jorge Luis Ferrero, ${ }^{1}$ Nuria Fernández, ${ }^{4}$ Luis Monge, ${ }^{4}$ \\ and Ángel Luis García-Villalón ${ }^{4}$ \\ ${ }^{1}$ Departamento de Cirugía General y Digestiva (Seccion B), Hospital Universitario "12 de Octubre", Universidad Complutense, \\ Avenida de Córdoba, s/n, 28041 Madrid, Spain \\ ${ }^{2}$ Departamento de Fisiología, Universidad de Valencia, Avenida Blasco Ibáñez 15, 46010 Valencia, Spain \\ ${ }^{3}$ INCLIVA, Instituto Investigación Sanitaria, Hospital Clínico Universitario, Avenida Blasco Ibáñez 15, 46010 Valencia, Spain \\ ${ }^{4}$ Departamento de Fisiología, Facultad de Medicina, Universidad Autónoma de Madrid, Arzobispo Morcillo 2, 28029 Madrid, Spain
}

Correspondence should be addressed to Ángel Luis García-Villalón; angeluis.villalon@uam.es

Received 22 April 2013; Revised 7 August 2013; Accepted 2 October 2013

Academic Editor: Gary E. Gallick

\begin{abstract}
Copyright (C) 2013 Eduardo Ferrero et al. This is an open access article distributed under the Creative Commons Attribution License, which permits unrestricted use, distribution, and reproduction in any medium, provided the original work is properly cited.

The aim of this study was to analyze whether tyrosine phosphorylation in tumoral arteries may modulate their vascular response. To do this, mesenteric arteries supplying blood flow to colorectal tumors or to normal intestine were obtained during surgery and prepared for isometric tension recording in an organ bath. Increasing tyrosine phosphorylation with the phosphatase inhibitor, sodium orthovanadate produced arterial contraction which was lower in tumoral than in control arteries, whereas it reduced the contraction to noradrenaline in tumoral but not in control arteries and reduced the relaxation to bradykinin in control but not in tumoral arteries. Protein expression of VEGF-A and of the VEGF receptor FLT1 was similar in control and tumoral arteries, but expression of the VEGF receptor KDR was increased in tumoral compared with control arteries. This suggests that tyrosine phosphorylation may produce inhibition of the contraction in tumoral mesenteric arteries, which may increase blood flow to the tumor when tyrosine phosphorylation is increased by stimulation of VEGF receptors.
\end{abstract}

\section{Introduction}

Tyrosine kinases are a family of protein kinases present in metazoans, which are mainly associated with receptors of growth factors such as vascular endothelial growth factor (VEGF), epidermal growth factor (EGF), and fibroblast growth factor (FGF) [1]. Tyrosine kinases have important roles in several cell functions as differentiation, proliferation, apoptosis, angiogenesis, and responses to neurotransmitters [2]. Tyrosine kinases also play a fundamental role in the development of malignant cells during cancer development, and therefore several inhibitors of tyrosine kinases have been added to the list of antitumoral agents available for cancer treatment [3].
Tyrosine phosphorylation may also regulate contraction of vascular smooth muscle. Vascular smooth muscle cells show levels of tyrosine kinase activity which are relatively high [4]. Inhibition of tyrosine phosphatase with sodium orthovanadate produced contraction of smooth muscles of rat aorta [5] or rat penile artery [6] and increased the contraction to hypoxia in sheep pulmonary veins [7] and to serotonin in rat basilar artery [8].

In tumoral tissues, tyrosine phosphorylation is often related to activation of growth factor receptors which have tyrosine kinase activity, including VEGF receptors which have a central role in cancer development [9]. VEGF acts on blood vessels mainly through two receptors: VEGF-R1/FLT1 and VEGF-R2/KDR, both of which have tyrosine kinase 
activity $[10,11]$. Expression of VEFG is increased in tumors [12] and in the plasma of cancer patients $[13,14]$. VEGF receptors also may be increased in tumors, either in the tumor cells or in the blood vessels supporting the tumor. Smith et al. [15] found that VEGFR-2 is overexpressed in blood vessels of colorectal, lung, and breast tumors, but not in the tumor cells. However, Amaya et al. [16] have reported increased KDR receptors in blood vessels and also in tumor cells of colorectal cancer. These studies have localized VEGF receptors in the microvasculature of the tumor and have not separated the expression according to the type of blood vessel, that is, artery, capillary, or vein. Most of the blood vessels in the microcirculation are capillaries and venules, which have little role in the regulation of blood flow, and there are not, to our knowledge, studies of the expression of VEGF or VEGF receptors specifically in the arteries supplying blood flow to the tumor.

Regulation of tumoral vasculature is an important factor in the development of solid tumors, as blood flow must increase in parallel with the growth of the tumor. The hypothesis of the present study is that tyrosine phosphorylation may play a role in the regulation of vasoconstriction and/or vasodilatation of the arteries supplying blood flow to the tumors. Therefore, we have studied the effect of increasing tyrosine phosphorylation on vasoconstriction and vasodilatation of arteries supplying colorectal tumors, comparing them with arteries supplying normal tissue. The inhibitors of tyrosine phosphatases such as vanadate increase tyrosine phosphorylation and reproduce the vascular effects of receptors with tyrosine kinase activity [17].

\section{Methods}

2.1. Collection of the Human Mesenteric Arteries. In this study, arteries $(0.7-1.5 \mathrm{~mm}$ in external diameter) from 13 patients diagnosed with colorectal tumour were used (mean age: $72 \pm$ 4 years, 7 males and 6 females). The study was approved by the local ethics committee and the informed consent from all the patients was obtained before they were allowed to participate. Arteries supplying blood flow to the tumour as well as arteries supplying the normal colon were dissected out at surgery from each patient and frozen on dry ice for RT-PCR and western blot techniques, or stored in cold isotonic saline solution for in vitro vascular response.

2.2. Recording of Vascular Response. After collection and once transported to the laboratory, the arteries were cut into $2 \mathrm{~mm}$ long segments and each segment was prepared for isometric tension recording in a $4 \mathrm{~mL}$ organ bath containing modified Krebs-Henseleit solution at $37^{\circ} \mathrm{C}(\mathrm{mM}): \mathrm{NaCl}, 115$; $\mathrm{KCl}, 4.6 ; \mathrm{KH}_{2} \mathrm{PO}_{4}, 1.2 ; \mathrm{MgSO}_{4}, 1.2 ; \mathrm{CaCl}_{2}, 2.5 ; \mathrm{NaHCO}_{3}, 25 ;$ glucose, 11. The solution was equilibrated with $95 \%$ oxygen and $5 \%$ carbon dioxide to a $\mathrm{pH}$ of 7.3-7.4. Briefly, two fine steel wires $(100 \mu \mathrm{m}$ in diameter) were passed through the lumen of the vascular segment, one wire was fixed to the organ bath wall while the other was connected to a strain gauge for isometric tension recording (Universal Transducing Cell UC3 and Statham Microscale Accessory
UL5, Statham Instruments, Inc.). This arrangement permits passive tension to be applied in a plane perpendicular to the long axis of the vascular cylinder. The changes in isometric force were recorded on a Macintosh computer using Chart v 3.6/s software and a MacLab/8e data acquisition system (ADInstruments). An optimal passive tension of $1 \mathrm{~g}$ was applied to the vascular segments, and then, they were allowed to equilibrate for $60-90 \mathrm{~min}$. Before beginning the experiment, the vascular segments were stimulated with potassium chloride $(50 \mathrm{mM})$ to determine the contractility of smooth muscle, and the segments which failed to contract at least $0.5 \mathrm{~g}$ were discarded.

To analyze the direct effect of tyrosine phosphorylation on the vascular tone of mesenteric arteries, cumulative doseresponse curves were recorded for sodium orthovanadate $\left(10^{-4}-10^{-2} \mathrm{M}\right)$ in the vascular segments from arteries supplying the tumour (tumoral) and from those supplying normal colon (control) in the same patients. This effect was also recorded in the presence of the inhibitor of tyrosine kinase genistein $\left(10^{-4} \mathrm{M}\right)$ to analyze whether the response was due to tyrosine phosphorylation. To study the effect of tyrosine phosphorylation in response to vasoconstrictor of vasodilator stimuli, the contraction to noradrenaline $\left(10^{-9}-10^{-4} \mathrm{M}\right)$ and to the endothelium-dependent vasodilator bradykinin $\left(10^{-9}\right.$ $\left.10^{-5} \mathrm{M}\right)$ was studied after treatment with orthovanadate $\left(10^{-3} \mathrm{M}\right)$ in control and tumoral arteries. Orthovanadate was added to the organ bath $30 \mathrm{~min}$ before the concentrationresponse curve to noradrenaline or bradykinin, and before recording the relaxation to bradykinin, the arteries were precontracted with $\mathrm{U} 46619\left(10^{-9}-10^{-8} \mathrm{M}\right)$ to reach a contractile tone of about 3-3.5 g.

Contraction in response to sodium orthovanadate and to noradrenaline was expressed as the percentage of the maximal contraction produced by potassium $(50 \mathrm{mM})$, whereas the relaxation in response to bradykinin was expressed as the percentage of the active tone achieved with U46619. In each concentration-response curve, the $\mathrm{pD}_{2}$ was calculated as the negative logarithm of the concentration producing $50 \%$ of the maximal response by geometric interpolation.

2.3. RNA Isolation and RT-PCR Analysis. Total RNA was isolated from frozen vascular segment by using TriPure Isolation Reagent (Roche, Group SA) protocol, as suggested by the manufacturer. RNA concentration and integrity were determined using RNA 6000 Nano LabChip in an Agilent 2100 Bioanalyzer. The reverse transcription was performed with the High Capacity RNA-to-cDNA Master Mix (Applied Biosystems). The primers used for amplification of cDNA were obtained from TaqMan Gene Expression Assays (Applied Biosystems, inventoried assays) for VEGFA (Hs03929005_m1), VEGFR1 (FLT1) (Hs01052961_m1), VRGFR2 (KDR) (Hs00911700_m1), and GAPDH (endogenous control 4352934E). Amplification of target cDNA was done using a 7900HT Fast Real-Time PCR System with the following standardized thermal cycling conditions: $50^{\circ} \mathrm{C}$ for $2 \mathrm{~min}, 95^{\circ} \mathrm{C}$ for $10 \mathrm{~min}$, followed by 40 cycles of $95^{\circ} \mathrm{C}$ for $15 \mathrm{sec}$ and $60^{\circ} \mathrm{C}$ for $1 \mathrm{~min}$. All RT-PCR reactions were run in duplicate. Threshold cycle 
(Ct) was determined for both target gene and GAPDH for each sample, and relative quantifying of both genes was determined with the 2-DDCt method [18].

2.4. Western Blot Analysis. The expression of VEGF-A, KDR, and FLT1 in vascular samples was measured by densitometry quantitation of immunoblots. Briefly, vascular tissues were homogenized in a lysis buffer (in $\mathrm{mM}$ ): 50 Tris- $\mathrm{HCl}, 125$ $\mathrm{NaCl}, 1$ EDTA, 1 EGTA, 1\% Nonidet (NP-40) containing $5 \%$ complete mini-tab cocktail protease inhibitor (Roche Biochemicals) and centrifuged at $10000 \mathrm{rpm}$ for $15 \mathrm{~min}$ at $4^{\circ} \mathrm{C}$. Protein concentration was determined using a modified Lowry method [19]. Then, $50 \mu \mathrm{g}$ of total protein was resolved in $12 \%$ SDS-PAGE and electrophoretically transferred onto a PVDF-membrane using Mini Trans-Blot cell (BioRad laboratories, CA, USA). Membranes were blocked in 5\% skim milk for $1 \mathrm{~h}$ at room temperature. After an overnight incubation at $4^{\circ} \mathrm{C}$ using diluted monoclonal antibodies from Sigma $(1: 1000)$, the membranes were incubated with $1: 2500$ diluted horseradish peroxidase-conjugated secondary antibody (Sigma-Aldrich). The blots were then visualized using ImmunoStar HRP Substrate Kit (Bio-Rad) according to manufacturer's instructions. Relative densities of the bands were analyzed using Image Gauge v 4.0, Fujifilm. The proteins were normalized with tubulin.

Antibodies are monoclonal anti-VEGF-A, monoclonal anti-VEGF receptor 1 (FLT1), monoclonal anti-VEGF receptor 2 (KDR), diluted at $(1: 1000)$, polyclonal anti-tubuline $(1: 1000)$ (Sigma Aldrich).

2.5. Statistical Analysis. The data are expressed as mean \pm standard error of the mean. The responses to orthovanadate, noradrenaline, and bradykinin in tumour and control vascular segments, treated and untreated with genistein or orthovanadate, were compared by two-way ANOVA followed by Bonferroni test to determine which comparisons were statistically significant. Genic and protein expression of VEGF, FLT1, and KDR in control and tumoral arteries were compared by paired Student's $t$-test.

2.6. Compounds Used. The compounds used were (all from Sigma) sodium orthovanadate $\left(\mathrm{Na}_{3} \mathrm{VO}_{4}\right)$; genistein (5,7dihydroxy-3-(4-hydroxyphenyl)-4H-benzopyran-4-one, 4,5,7-trihydroxy-isoflavone); L-noradrenaline ((1R)-4-(2amino-1-hydroxyethyl)-1,2-benzenediol); bradykinin acetate (Arg-Pro-Pro-Gly-Phe-Ser-Pro-Phe-Arg), U46619 (9,11dideoxy-11 $\alpha, 9 \alpha$-epoxymethano prostaglandin $\mathrm{F} 2 \alpha$ ).

\section{Results and Discussion}

Stimulation with potassium chloride $(50 \mathrm{mM})$ produced a similar contraction in tumoral $(3.27 \pm 0.22 \mathrm{~g})$ and control $(3.18 \pm 0.28 \mathrm{~g})$ arteries. Sodium orthovanadate produced concentration-dependent contraction, which was smaller in tumoral $(n=10)$ compared to control $(n=9)$ arteries (Figure 1). This contraction to orthovanadate was reduced by genistein, both in tumoral and control arteries $(n=4$ in both groups).

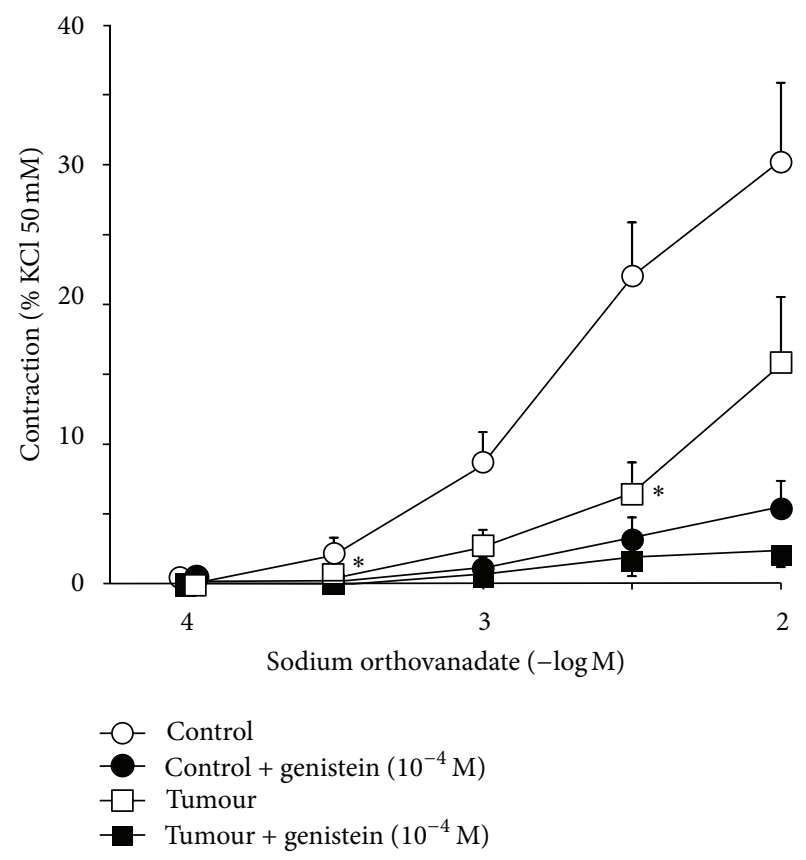

FIgURE 1: Contraction in response to sodium orthovanadate $\left(10^{-4}\right.$ $10^{-2} \mathrm{M}$ ) of mesenteric arteries supplying colorectal tumours (tumor, $n=10$ ) and those supplying normal colon (control, $n=9$ ), in the absence or in the presence of genistein $\left(10^{-4} \mathrm{M}, n=4\right)$. Values are represented as mean \pm SEM. ${ }^{*} P<0.05$ statistically significant versus control.

Noradrenaline also produced concentration-dependent contraction, which was similar in control and tumoral arteries $\left(\mathrm{pD}_{2}=6.20 \pm 0.07, n=6\right.$ versus $6.52 \pm 0.23, n=$ 6 , resp.) (Figure 2). In control arteries, pretreatment with sodium orthovanadate did not modify the contraction to noradrenaline $\left(\mathrm{pD}_{2}=6.13 \pm 0.35, n=7\right)$, whereas in tumoral arteries, the contraction to noradrenaline in the segments treated with orthovanadate was smaller $\left(\mathrm{pD}_{2}=5.68 \pm 0.12\right.$, $n=6, P<0.05)$ than that in untreated segments.

In the segments precontracted with U46619, bradykinin produced concentration-dependent relaxation, which was similar in the control and tumoral arteries $\left(\mathrm{pD}_{2}=6.89 \pm\right.$ $0.30, n=7$ versus $7.11 \pm 0.24, n=7$, resp.) (Figure 3 ). Treatment with sodium orthovanadate reduced this relaxation in control arteries $\left(\mathrm{pD}_{2}=6.00 \pm 0.15, n=8, P<0.05\right)$; however, in tumoral arteries, this treatment did not modify the relaxation to bradykinin $\left(\mathrm{pD}_{2}=6.67 \pm 0.27, n=8\right)$. The contractile tone produced by U46619 was similar in control and tumoral arteries, with and without pretreatment with sodium orthovanadate.

Quantitative PCR-RT analysis revealed a significant decrease in VEGF-A expression in tumor samples compared to the control $(1.18 \pm 0.20$ versus $0.36 \pm 0.06, P<0.05)$. We have also determined the expression of KDR and FLT1, the main receptors of VEGF-A in the arteries [20]. Compared with the control, the vascular mRNA gene expression of KDR and FLT1 from tumor samples was significantly downregulated (60\% and 64\%, resp., $P<0.05)$. As a control, the expression of GAPDH was measured in parallel using the same mRNA samples (Figure 4). 


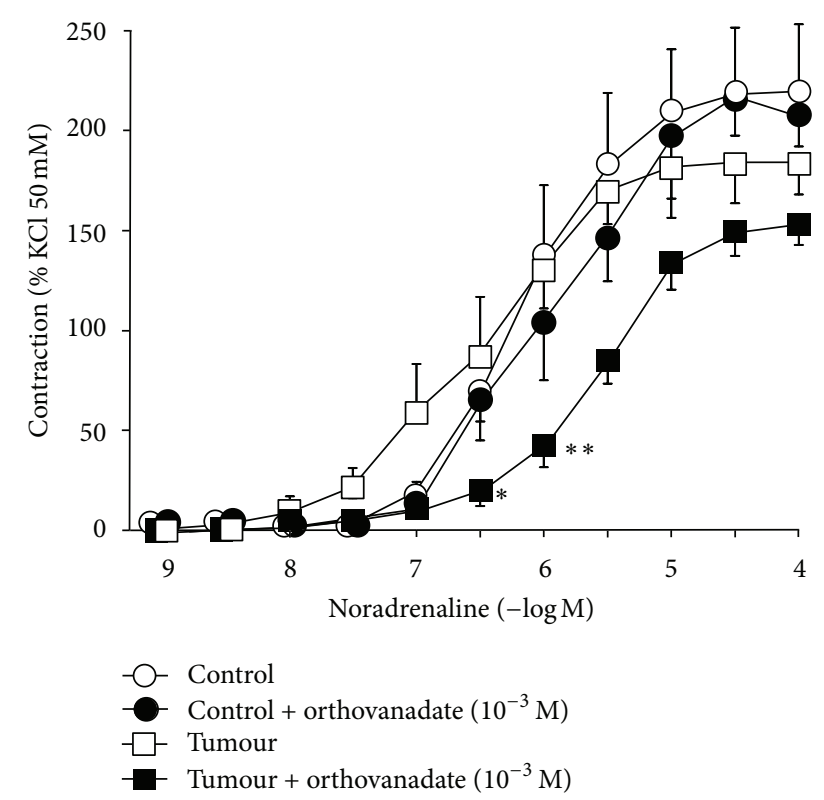

FIGURE 2: Contraction in response to noradrenaline $\left(10^{-9}-10^{-4} \mathrm{M}\right)$ of mesenteric arteries supplying colorectal tumours (tumour, $n=6$ ) and those supplying normal colon (control, $n=6$ ), untreated or treated $(n=6-7)$ with sodium orthovanadate $\left(10^{-3} \mathrm{M}\right)$. Values are represented as mean \pm SEM. ${ }^{* *} P<0.01 ;{ }^{*} P<0.05$ statistically significant versus untreated segments.

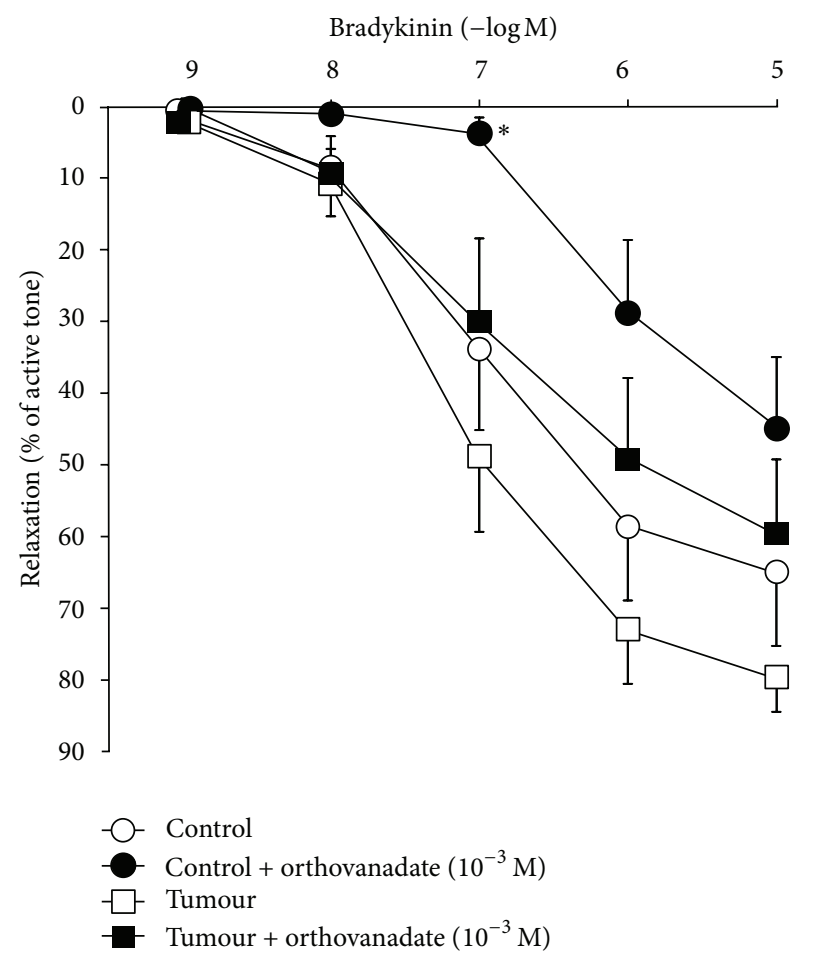

FIGURE 3: Relaxation in response to bradykinin $\left(10^{-9}-10^{-5} \mathrm{M}\right)$ of mesenteric arteries supplying colorectal tumours (tumour, $n=7$ ) and those supplying normal colon (control, $n=7$ ), precontracted with U46619 and untreated or treated $(n=8)$ with sodium orthovanadate $\left(10^{-3} \mathrm{M}\right)$. Values are represented as mean \pm SEM. ${ }^{*} P<0.05$ statistically significant versus untreated segments.

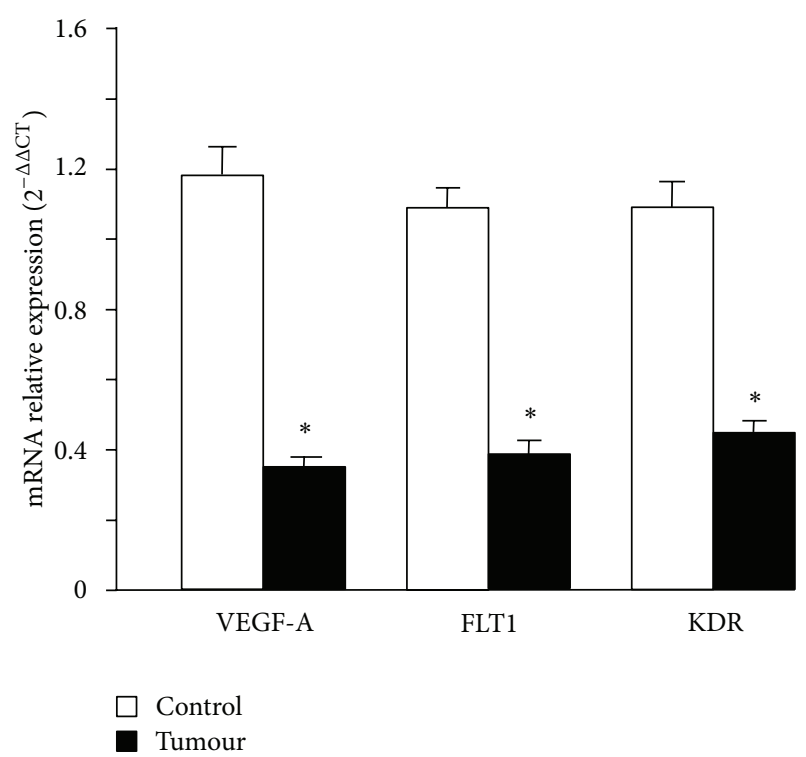

FIGURE 4: RT-PCR analysis of mRNA expression for VEGF-A, FLT1, and KDR in mesenteric arteries supplying colorectal tumours (tumour, $n=6$ ) and those supplying normal colon (control, $n=6$ ). Values were normalized to GAPDH mRNA expression. Data are presented as mean \pm SEM. ${ }^{*} P<0.05$ statistically significant versus control samples.

Next we investigated the VEGF-A, FLT1, and KDR protein expression by western blot analysis. We found that protein expression of VEGF-A and FLT1 was similar in control and tumor vascular tissues. However, in samples from tumors, there is a significant increase in the protein expression of KDR (Figure 5).

This study finds that tyrosine phosphorylation may underlie a differential regulation of vascular function in colorectal tumors. Tyrosine phosphorylation is known to produce vasoconstriction of vascular [5] and nonvascular [21-24] smooth muscles. In our study, inhibition of tyrosine phosphatases by orthovanadate indeed produced vasoconstriction of mesenteric arteries. This contraction was inhibited by the tyrosine kinase inhibitor genistein, suggesting that it is due to increased tyrosine phosphorylation. The contraction produced by tyrosine phosphorylation has been related to $\mathrm{Ca}^{2+}$ influx $[6,25]$ or increased sensitivity to $\mathrm{Ca}^{2+}$ of the intracellular contractile mechanisms [26, 27].

Although orthovanadate contracted both control and tumoral arteries, the contraction was smaller in tumoral arteries, suggesting a reduced contractile effect of tyrosine phosphorylation in these arteries. Also, we have found that orthovanadate reduced the contraction to noradrenaline in tumoral arteries but not in control arteries. This contrasts with observations in rabbit aorta and mesenteric arteries, in which tyrosine phosphorylation increases adrenergic vasoconstriction [28]; therefore, the inhibitory effect observed in the present study may be specific for tumoral arteries. If tyrosine phosphorylation has an inhibitory effect in tumoral but not in normal arteries, it might also explain the small contraction produced by orthovanadate in tumoral arteries, 


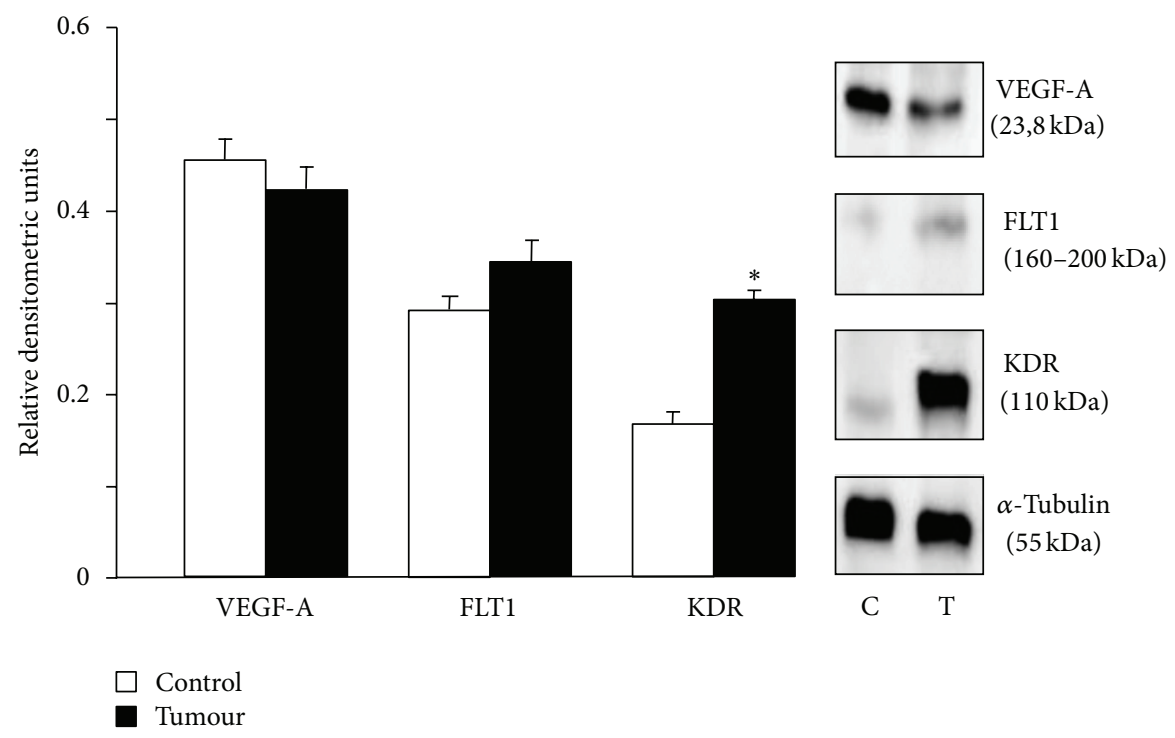

FiguRE 5: Protein expression in mesenteric arteries supplying colorectal tumours (T, $n=10)$ and those supplying normal colon (C, $n=10)$. VEGF-A, FLT1, KDR, and $\alpha$-tubuline expression was determined by western blot. Data are presented as means \pm SEM. ${ }^{*} P<0.05$ statistically significant versus control samples.

as the inhibitory effect might counteract the vasoconstriction observed in control arteries.

Orthovanadate also reduced endothelium-dependent vasodilatation in control mesenteric arteries. The effects of tyrosine phosphorylation on the endothelium may be mixed. Tyrosine kinases may enhance the release of endothelial nitric oxide [8, 29-33]. However, tyrosine phosphorylation has been also related to the endothelial dysfunction in diabetes [33], hyperhomocysteinemia [34], and Raynaud's phenomenon [35]. Our results agree with those latter studies, as in control mesenteric arteries, orthovanadate reduced endothelium-dependent vasodilatation to bradykinin. However, in tumoral arteries orthovanadate did not reduce significantly this relaxation. This may agree with a possible relaxing effect of tyrosine phosphorylation in these arteries, as we have hypothesized above, which could compensate for the relaxation impairment observed in control arteries.

This possible inhibitory effect of tyrosine phosphorylation in tumoral arteries may be surprising, as the activation of tyrosine phosphorylation produces vasoconstriction in normal arteries [8, 36-39]. However, some receptors with tyrosine kinase activity may produce vasodilatation. Vascular endothelial growth factor (VEGF) produces vasodilatation in human [40], pig [41], or rat [42] coronary circulation, human placental circulation [43], bovine pulmonary arteries [44], and human mammary and radial arteries [45, 46]. Indeed, we have observed that application of VEGF produced relaxation of precontracted human mesenteric blood vessels (unpublished observations). Vanadate compounds are known to increase phosphorylation of VEGFR2/KDR receptors [47-49] and activate their effects $[47,49]$. Therefore, as VEGFR2/KDR receptors may produce vasodilatation [5052] and may be activated by vanadate, this may explain the inhibitory effect of orthovanadate observed in tumoral arteries. Also, we have found in this study that the expression of
KDR receptors is increased in tumoral arteries and this might explain why this inhibitory effect is apparent in tumoral but not in control arteries. Expression of VEGFR-1/Flt1 [53, 54], VEGFR2/KDR $[15,55,56]$, or both receptor subtypes [57-60] is increased in several types of tumors including colorectal ones [61-63]. However, the present study is the first, to our knowledge, showing increased expression of VEGF receptors in the arteries supplying blood flow to the tumor. These arteries are not mutated, while tumoral cells are, but may be altered by factors released in the microenvironment of the tumor [64]. It has been described that the arteries surrounding the tumor show differences in receptor expression compared with normal arteries from the same subject [65]. As it has been described that VEGF receptors are expressed mainly in the endothelium [66], this increased expression in tumoral arteries might explain why tyrosine phosphorylation has a partly inhibitory effect in these arteries but not in normal arteries. In normal arteries, tyrosine phosphorylation would produce contraction of smooth muscle, as we have observed, but in tumoral arteries, due to the increased expression of VEGF receptors, it would activate also relaxing mechanisms in endothelial cells. Contrasting with the fact that in tumoral arteries protein expression of FLT1 and KDR was unchanged or increased, respectively, the genic expression of these receptors was reduced in tumoral arteries. It has been shown that the VEGF may have opposite effects on protein and mRNA expression of FLT1 and KDR receptors in cultured human umbilical vein endothelial cells, which may be an adaptive mechanism to compensate for receptor desensitization and allow recovery of responsiveness to VEGF [64].

\section{Conclusions}

These results may have relevance, as the medium in the vicinity of the tumour may be rich in factors that activate 
tyrosine kinases and inhibitors of tyrosine kinase are used as antitumoral agents. Our results suggest that in normal arteries, tyrosine phosphorylation may produce vasoconstriction, whereas in the arteries supplying the tumor, it may produce inhibition of contraction. This may redistribute blood flow to the tumor, thus facilitating its growth.

\section{Conflict of Interests}

None of the coauthors have any conflict of interests or direct financial relation with any of the trademarks mentioned in this paper.

\section{Acknowledgments}

The authors are indebted to María Ester Martínez and Hortensia Fernández-Lomana for their invaluable technical assistance. This work was financed by Fondo de Investigaciones Sanitarias (PS09/00394) and Fundación Mutua Madrileña (AP57242009).

\section{References}

[1] M. Choura and A. Rebaï, "Receptor tyrosine kinases: from biology to pathology," Journal of Receptors and Signal Transduction, vol. 31, no. 6, pp. 387-394, 2011.

[2] T. Hunter, "The Croonian Lecture 1997. The phosphorylation of proteins on tyrosine: its role in cell growth and disease," Philosophical Transactions of the Royal Society B, vol. 353, no. 1368, pp. 583-605, 1998.

[3] S. Madhusudan and T. S. Ganesan, "Tyrosine kinase inhibitors in cancer therapy," Clinical Biochemistry, vol. 37, no. 7, pp. 618635, 2004.

[4] G. Elberg, J. Li, A. Leibovitch, and Y. Shechter, "Non-receptor cytosolic protein tyrosine kinases from various rat tissues," Biochimica et Biophysica Acta, vol. 1269, no. 3, pp. 299-306, 1995.

[5] J. Yu, K. Mizumoto, T. Kakutani, A. Hasegawa, K. Ogawa, and Y. Hatano, "Comparison of the effects of isoflurane and sevoflurane on protein tyrosine phosphorylation-mediated vascular contraction," Acta Anaesthesiologica Scandinavica, vol. 49, no. 6, pp. 852-858, 2005.

[6] N. Villalba, A. Kun, E. Stankevicius, and U. Simonsen, "Role for tyrosine kinases in contraction of rat penile small arteries," Journal of Sexual Medicine, vol. 7, no. 6, pp. 2086-2095, 2010.

[7] Ö. Uzun and A. T. Demiryürek, "Involvement of tyrosine kinase pathway in acute hypoxic vasoconstriction in sheep isolated pulmonary vein," Vascular Pharmacology, vol. 40, no. 3, pp. 175181, 2003.

[8] T. Kitazono, S. Ibayashi, T. Nagao, K. Fujii, T. Kagiyama, and M. Fujishima, "Role of tyrosine kinase in dilator responses of rat basilar artery in vivo," Hypertension, vol. 31, no. 3, pp. 861-865, 1998.

[9] P. Carmeliet, "VEGF as a key mediator of angiogenesis in cancer," Oncology, vol. 69, supplement 3, pp. 4-10, 2005.

[10] A.-K. Olsson, A. Dimberg, J. Kreuger, and L. Claesson-Welsh, "VEGF receptor signalling-in control of vascular function," Nature Reviews Molecular Cell Biology, vol. 7, no. 5, pp. 359-371, 2006.

[11] E. Stuttfeld and K. Ballmer-Hofer, "Structure and function of VEGF receptors,” IUBMB Life, vol. 61, no. 9, pp. 915-922, 2009.
[12] N. Ferrara, "Vascular endothelial growth factor: basic science and clinical progress," Endocrine Reviews, vol. 25, no. 4, pp. 581611, 2004.

[13] V. Dymicka-Piekarska, K. Guzinska-Ustymowicz, A. Kuklinski, and H. Kemona, "Prognostic significance of adhesion molecules (sICAM-1, sVCAM-1) and VEGF in colorectal cancer patients," Thrombosis Research, vol. 129, no. 4, pp. e47-e50, 2012.

[14] J. E. Peterson, D. Zurakowski, J. E. Italiano Jr. et al., "VEGF, PF4 and PDGF are elevated in platelets of colorectal cancer patients," Angiogenesis, vol. 15, no. 2, pp. 265-273, 2012.

[15] N. R. Smith, D. Baker, N. H. James et al., "Vascular endothelial growth factor receptors VEGFR-2 and VEGFR-3 are localized primarily to the vasculature in human primary solid cancers," Clinical Cancer Research, vol. 16, no. 14, pp. 3548-3561, 2010.

[16] H. Amaya, N. Tanigawa, C. Lu et al., "Association of vascular endothelial growth factor expression with tumor angiogenesis, survival and thymidine phosphorylase/platelet-derived endothelial cell growth factor expression in human colorectal cancer," Cancer Letters, vol. 119, no. 2, pp. 227-235, 1997.

[17] A. K. Srivastava, "Protein tyrosine phosphorylation in cardiovascular system," Molecular and Cellular Biochemistry, vol. 149150, pp. 87-94, 1995.

[18] D. F. Sellitti, E. Puggina, C. Lagranha et al., “TGF- $\beta$-like transcriptional effects of thyroglobulin $(\mathrm{Tg})$ in mouse mesangial cells," Endocrine Journal, vol. 54, no. 3, pp. 449-458, 2007.

[19] G. L. Peterson, "A simplification of the protein assay method of Lowry et al. Which is more generally applicable," Analytical Biochemistry, vol. 83, no. 2, pp. 346-356, 1977.

[20] L. B. Jakeman, M. Armanini, H. S. Phillips, and N. Ferrara, "Developmental expression of binding sites and messenger ribonucleic acid for vascular endothelial growth factor suggests a role for this protein in vasculogenesis and angiogenesis," Endocrinology, vol. 133, no. 2, pp. 848-859, 1993.

[21] S. Alcón, P. J. Camello, L. J. García, and M. J. Pozo, “Activation of tyrosine kinase pathway by vanadate in gallbladder smooth muscle," Biochemical Pharmacology, vol. 59, no. 9, pp. 1077-1089, 2000.

[22] L. Grasa, M. P. Arruebo, M. A. Plaza, and M. D. Murillo, “The role of tyrosine kinase in prostaglandin E2 and vanadate-evoked contractions in rabbit duodenum in vitro," Journal of Physiology and Pharmacology, vol. 57, no. 2, pp. 279-289, 2006.

[23] H. E. Kafl and H. A. Elkashef, "Effect of sodium orthovanadate on the urinary bladder rings isolated from normal and hyperglycemic rats," Pakistan Journal of Pharmaceutical Sciences, vol. 19, no. 3, pp. 195-201, 2006.

[24] L. Zhao, Z. Wang, Y.-C. Ruan, and W.-L. Zhou, "Cellular mechanism underlying the facilitation of contractile response of vas deferens smooth muscle by sodium orthovanadate," Molecular and Cellular Biochemistry, vol. 366, no. 1-2, pp. 149$157,2012$.

[25] S. Wijetunge, C. Aalkjaer, M. Schachter, and A. D. Hughes, "Tyrosine kinase inhibitors block calcium channel currents in vascular smooth muscle cells," Biochemical and Biophysical Research Communications, vol. 189, no. 3, pp. 1620-1623, 1992.

[26] H. Masui and I. Wakabayashi, "Tyrosine phosphorylation increases $\mathrm{Ca}_{2}^{+}$sensitivity of vascular smooth muscle contraction," Life Sciences, vol. 68, no. 4, pp. 363-372, 2000.

[27] J. Di Salvo, G. Pfitzer, and L. A. Semenchuk, "Protein tyrosine phosphorylation, cellular $\mathrm{Ca}_{2}^{+}$, and $\mathrm{Ca}^{+}$sensitivity for contraction of smooth muscle," Canadian Journal of Physiology and Pharmacology, vol. 72, no. 11, pp. 1434-1439, 1994. 
[28] B. J. Adegunloye, X. Su, E. V. Camper, and R. S. Moreland, "Sensitivity of rabbit aorta and mesenteric artery to norepinephrine: role of tyrosine kinases," European Journal of Pharmacology, vol. 476, no. 3, pp. 201-209, 2003.

[29] T. Hisayama, K. Kida, K. Imada, and H. Moritoki, "Tyrosine kinase may participate in $\mathrm{Ca}_{2}^{+}$entry for endothelial nitric oxide production," Japanese Journal of Pharmacology, vol. 67, no. 2, pp. 181-183, 1995.

[30] J. M. Muller, M. J. Davis, and W. M. Chilian, "Coronary arteriolar flow-induced vasodilation signals through tyrosine kinase," American Journal of Physiology-Heart and Circulatory Physiology, vol. 270, no. 6, part 2, pp. H1878-H1884, 1996.

[31] R. Nakaike, H. Shimokawa, M. K. Owada et al., "Vanadate causes synthesis of endothelium-derived NO via pertussis toxin- sensitive G protein in pigs," American Journal of Physiology-Heart and Circulatory Physiology, vol. 271, no. 1, part 2, pp. H296-H302, 1996.

[32] S. Sharma, M. Singh, and P. L. Sharma, "Mechanism of attenuation of diabetes mellitus and hypercholesterolemia induced vascular endothelial dysfunction by protein tyrosine phosphatase inhibition," Vascular Pharmacology, vol. 54, no. 3-6, pp. 80-87, 2011.

[33] M. H. M. Yousif, I. F. Benter, and S. Akhtar, "The role of tyrosine kinase-mediated pathways in diabetes-induced alterations in responsiveness of rat carotid artery," Autonomic and Autacoid Pharmacology, vol. 25, no. 2, pp. 69-78, 2005.

[34] D. I. Shah and M. Singh, "Inhibition of protein tyrosin phosphatase improves vascular endothelial dysfunction," Vascular Pharmacology, vol. 44, no. 3, pp. 177-182, 2006.

[35] P. B. Furspan, S. Chatterjee, M. D. Mayes, and R. R. Freedman, "Cooling-induced contraction and protein tyrosine kinase activity of isolated arterioles in secondary Raynaud's phenomenon," Rheumatology, vol. 44, no. 4, pp. 488-494, 2005.

[36] C. Fetscher, H. Chen, R. F. Schäfers, G. Wambach, G. Heusch, and M. C. Michel, "Modulation of noradrenaline-induced microvascular constriction by protein kinase inhibitors," Naunyn-Schmiedeberg's Archives of Pharmacology, vol. 363, no. 1, pp. 57-65, 2001.

[37] C. Liu, T. Tazzeo, H. Lippton, and L. J. Janssen, "Role of tyrosine phosphorylation in U46619-induced vasoconstriction of pulmonary vasculature and its modulation by genistein, daidzein, and equol," Journal of Cardiovascular Pharmacology, vol. 50, no. 4, pp. 441-448, 2007.

[38] K. Tasaki, M. Hori, H. Ozaki, H. Karaki, and I. Wakabayashi, "Difference in signal transduction mechanisms involved in 5hydroxytryptamine- and U46619-induced vasoconstrictions," Journal of Smooth Muscle Research, vol. 39, no. 5, pp. 107-117, 2003.

[39] M. Watanabe, M. Doi, K. Sasaki, and A. Ogawa, "Modulatory role of protein tyrosine kinase activation in the receptorinduced contractions of the bovine cerebral artery," Neurologia Medico-Chirurgica, vol. 38, no. 2, pp. 75-82, 1998.

[40] C. Métais, L. I. Jianyi, L. I. Jian, M. Simons, and F. W. Sellke, "Effects of coronary artery disease on expression and microvascular response to VEGF," American Journal of PhysiologyHeart and Circulatory Physiology, vol. 275, no. 4, pp. H1411H1418, 1998.

[41] F. W. Sellke, S. Y. Wang, A. Stamler et al., "Enhanced microvascular relaxations to VEGF and bFGF in chronically ischemic porcine myocardium," American Journal of Physiology-Heart and Circulatory Physiology, vol. 271, no. 2, pp. H713-H720, 1996.
[42] A. J. LeBlanc, R. D. Shipley, L. S. Kang, and J. M. Muller-Delp, "Age impairs Flk-1 signaling and NO-mediated vasodilation in coronary arterioles," American Journal of Physiology-Heart and Circulatory Physiology, vol. 295, no. 6, pp. H2280-H2288, 2008.

[43] P. Brownbill, G. C. McKeeman, J. C. Brockelsby, I. P. Crocker, and C. P. Sibley, "Vasoactive and permeability effects of vascular endothelial growth factor-165 in the term in vitro dually perfused human placental lobule," Endocrinology, vol. 148, no. 10, pp. 4734-4744, 2007.

[44] E. R. Jacobs, D. Zhu, S. Gruenloh, B. Lopez, and M. Medhora, "VEGF-induced relaxation of pulmonary arteries is mediated by endothelial cytochrome P-450 hydroxylase," American Journal of Physiology-Lung Cellular and Molecular Physiology, vol. 291, no. 3, pp. L369-L377, 2006.

[45] M. H. Liu, H. Jin, H. S. Floten, Z. Ren, A. P. Yim, and G. W. He, "Vascular endothelial growth factor-mediated, endotheliumdependent relaxation in human internal mammary artery," Annals of Thoracic Surgery, vol. 73, no. 3, p. 819824, 2002.

[46] W. Wei, Z.-W. Chen, Q. Yang et al., "Vasorelaxation induced by vascular endothelial growth factor in the human internal mammary artery and radial artery," Vascular Pharmacology, vol. 46, no. 4, pp. 253-259, 2007.

[47] A. N. Carr, M. G. Davis, E. Eby-Wilkens et al., "Tyrosine phosphatase inhibition augments collateral blood flow in a rat model of peripheral vascular disease," American Journal of Physiology-Heart and Circulatory Physiology, vol. 287, no. 1, pp. H268-H276, 2004.

[48] J. Oshikawa, N. Urao, H. W. Kim et al., "Extracellular SODderived $\mathrm{H}_{2} \mathrm{O}_{2}$ promotes VEGF signaling in caveolae/lipid rafts and post-ischemic angiogenesis in mice," PLoS ONE, vol. 5, no. 4, Article ID e10189, 2010.

[49] M. Sugano, K. Tsuchida, and N. Makino, "A protein tyrosine phosphatase inhibitor accelerates angiogenesis in a rat model of hindlimb ischemia," Journal of Cardiovascular Pharmacology, vol. 44, no. 4, pp. 460-465, 2004.

[50] W. Wei, H. Jin, Z.-W. Chen, T. F. Zioncheck, A. P. C. Yim, and G.-W. He, "Vascular endothelial growth factor-induced nitric oxide-and PGI 2-dependent relaxation in human internal mammary arteries: a comparative study with KDR and Flt-1 selective mutants," Journal of Cardiovascular Pharmacology, vol. 44, no. 5, pp. 615-621, 2004.

[51] B. Li, A. K. Ogasawara, R. Yang et al., "KDR (VEGF receptor 2 ) is the major mediator for the hypotensive effect of VEGF," Hypertension, vol. 39, no. 6, pp. 1095-1100, 2002.

[52] H. He, V. J. Venema, X. Gu, R. C. Venema, M. B. Marrero, and R. B. Caldwell, "Vascular endothelial growth factor signals endothelial cell production of nitric oxide and prostacyclin through Flk-1/KDR activation of c-Src," The Journal of Biological Chemistry, vol. 274, no. 35, pp. 25130-25135, 1999.

[53] H. Sartelet, M. Decaussin, G. Devouassoux et al., "Expression of vascular endothelial growth factor (VEGF) and its receptors (VEGF-R1 [Flt-1] and VEGF-R2 [KDR/Flk-1]) in tumorlets and in neuroendocrine cell hyperplasia of the lung," Human Pathology, vol. 35, no. 10, pp. 1210-1217, 2004.

[54] M. Schmidt, H.-U. Voelker, M. Kapp, J. Dietl, and U. Kammerer, "Expression of VEGFR-1 (Flt-1) in breast cancer is associated with VEGF expression and with node-negative tumour stage," Anticancer Research, vol. 28, no. 3, pp. 1719-1724, 2008. 
[55] J. C. Reubi, A. Fleischmann, B. Waser, and R. Rehmann, "Concomitant vascular GRP-receptor and VEGF-receptor expression in human tumors: molecular basis for dual targeting of tumoral vasculature," Peptides, vol. 32, no. 7, pp. 1457-1462, 2011.

[56] H. Takahashi and M. Shibuya, "The vascular endothelial growth factor (VEGF)/VEGF receptor system and its role under physiological and pathological conditions," Clinical Science, vol. 109, no. 3, pp. 227-241, 2005.

[57] H. Huang, J. Held-Feindt, R. Buhl, H. M. Mehdorn, and R. Mentlein, "Expression of VEGF and its receptors in different brain tumors," Neurological Research, vol. 27, no. 4, pp. 371-377, 2005.

[58] B. J. Ljungberg, J. Jacobsen, S. H. Rudolfsson, G. Lindh, K. Grankvist, and T. Rasmuson, "Different vascular endothelial growth factor (VEGF), VEGF-receptor 1 and -2 mRNA expression profiles between clear cell and papillary renal cell carcinoma," BJU International, vol. 98, no. 3, pp. 661-667, 2006.

[59] J. M. Mehnert, M. M. McCarthy, L. Jilaveanu et al., "Quantitative expression of VEGF, VEGF-R1, VEGF-R2, and VEGF-R3 in melanoma tissue microarrays," Human Pathology, vol. 41, no. 3 , pp. 375-384, 2010.

[60] J. Pallares, F. Rojo, J. Iriarte, J. Morote, L. I. Armadans, and I. de Torres, "Study of microvessel density and the expression of the angiogenic factors VEGF, bFGF and the receptors Flt-1 and FLK-1 in benign, premalignant and malignant prostate tissues," Histology and Histopathology, vol. 21, no. 8, pp. 857-865, 2006.

[61] Y. Harada, Y. Ogata, and K. Shirouzu, "Expression of vascular endothelial growth factor and its receptor KDR (kinase domaincontaining receptor)/Flk-1 (fetal liver kinase-1) as prognostic factors in human colorectal cancer," International Journal of Clinical Oncology, vol. 6, no. 5, pp. 221-228, 2001.

[62] N. T. Okita, Y. Yamada, D. Takahari et al., "Vascular endothelial growth factor receptor expression as a prognostic marker for survival in colorectal cancer," Japanese Journal of Clinical Oncology, vol. 39, no. 9, pp. 595-600, 2009.

[63] Y. Yin, L.-Y. Cao, W.-Q. Wu, H. Li, Y. Jiang, and H.-F. Zhang, "Blocking effects of siRNA on VEGF expression in human colorectal cancer cells," World Journal of Gastroenterology, vol. 16, no. 9, pp. 1086-1092, 2010.

[64] D. Wang, D. B. Donner, and R. S. Warren, "Homeostatic modulation of cell surface KDR and Flt1 expression and expression of the vascular endothelial cell growth factor (VEGF) receptor mRNAs by VEGF," The Journal of Biological Chemistry, vol. 275, no. 21, pp. 15905-15911, 2000.

[65] E. Ferrero, M. Labalde, N. Fernandez et al., "Response to endothelin-1 in arteries from human colorectal tumours: role of endothelin receptors," Experimental Biology and Medicine, vol. 233, no. 12, pp. 1602-1607, 2008.

[66] G. Neufeld, T. Cohen, S. Gengrinovitch, and Z. Poltorak, "Vascular endothelial growth factor (VEGF) and its receptors," FASEB Journal, vol. 13, no. 1, pp. 9-22, 1999. 


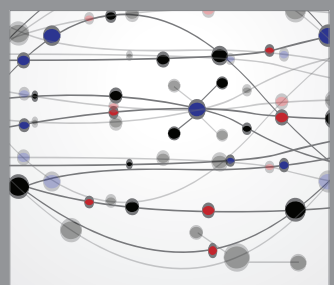

The Scientific World Journal
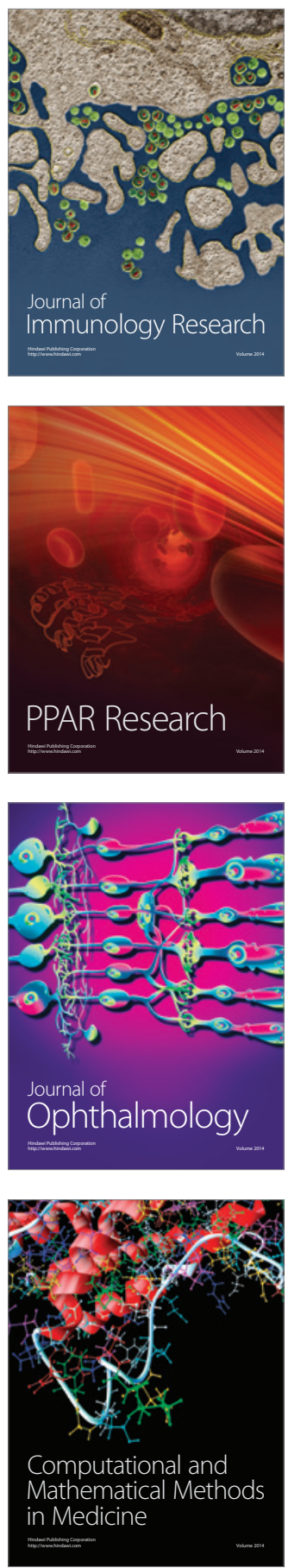

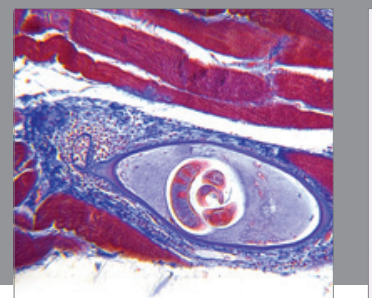

Gastroenterology

Research and Practice
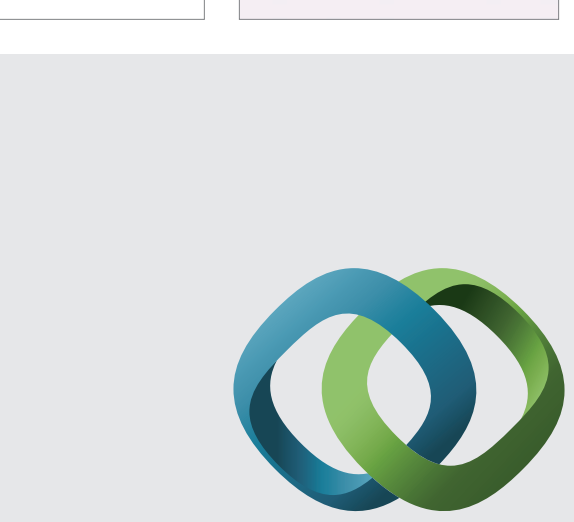

\section{Hindawi}

Submit your manuscripts at

http://www.hindawi.com
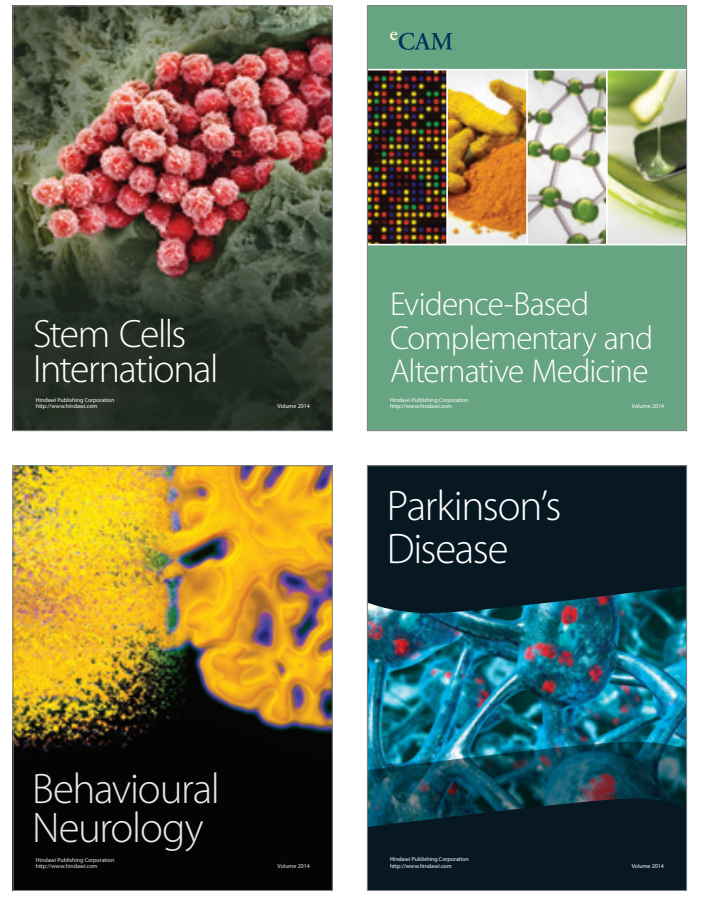
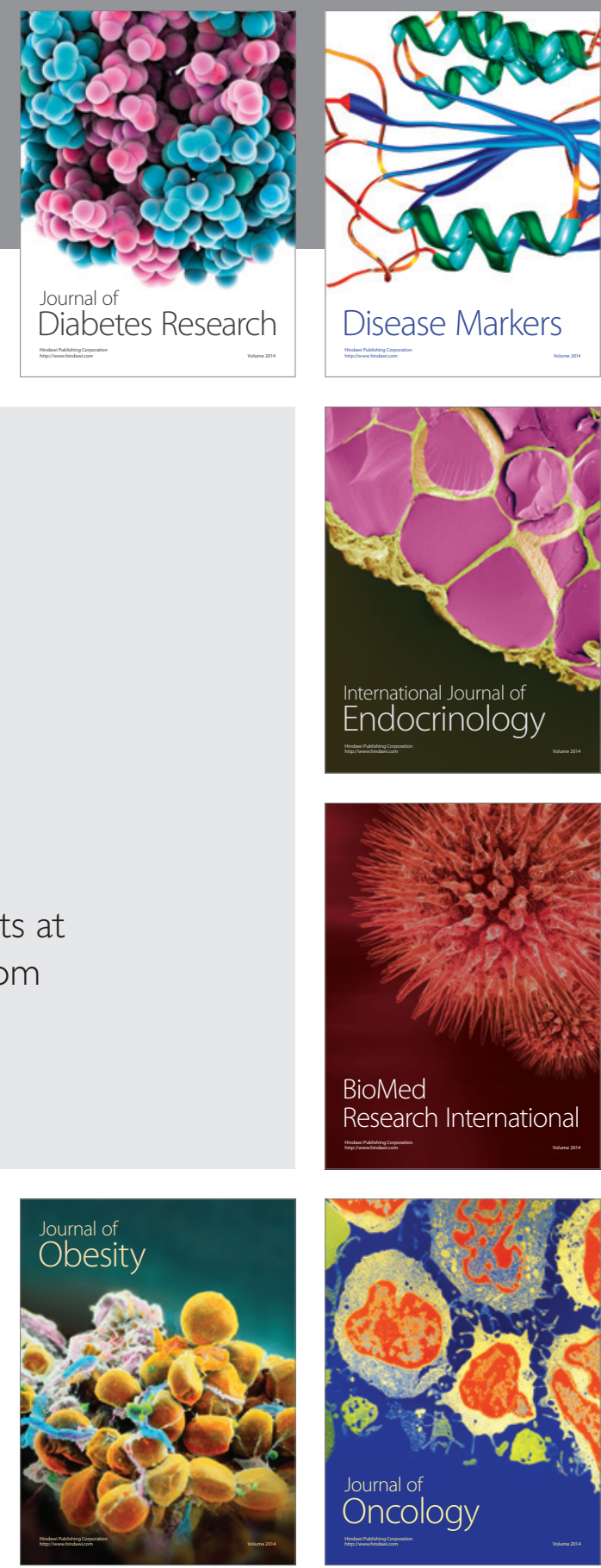

Disease Markers
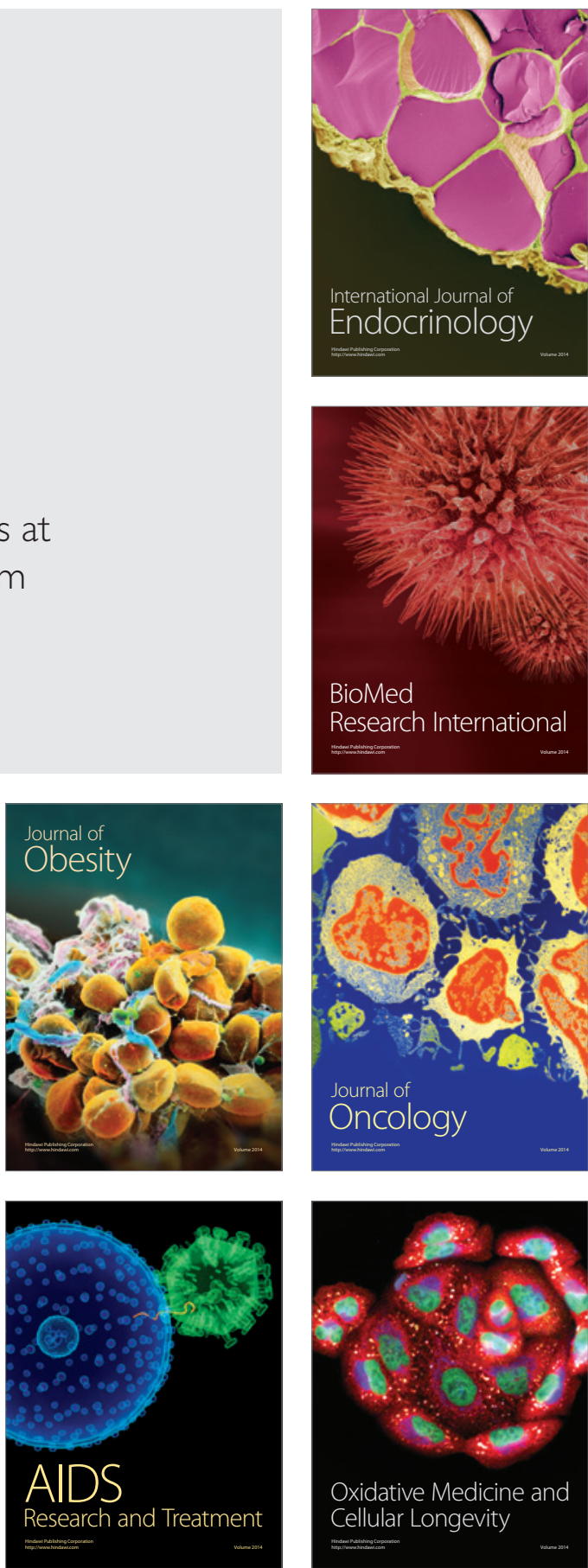